\title{
Special issue dedicated to William Fenical: a pioneer in marine/ marine-derived microbial chemistry
}

\author{
Hiroshi Tomoda ${ }^{1}$ James B. McAlpine ${ }^{2}$ \\ Received: 25 May 2020 / Accepted: 27 May 2020 / Published online: 27 July 2020 \\ (c) The Author(s), under exclusive licence to the Japan Antibiotics Research Association 2020
}

William (Bill) Fenical, a native Chicagoan, born June 1941, did all of his academic training and developed his career in California, with a BS from California State Polytechnic University (San Luis Obispo), MS from San José State University, and a PhD from UC Riverside, where he continued for a year's postdoctoral studies. After a year in Industry and a couple of years teaching, he joined Scripps Institute of Oceanography (SIO) at the University of California, San Diego, in 1973, and rapidly established himself as an expert in marine natural products.

Bill loves the sea and keeps a boat in San Diego harbor. One of us has been fortunate to be taken on a trip on it several years ago.

In the late 1980s, he took on Paul Jensen, a microbiologist, as a graduate student; Paul is now a professor at the Center for Marine Biotechnology \& Biomedicine at SIO. They became an incredibly productive partnership, studying marine-derived microbes and their secondary metabolites. Notably this led to cyclomarin, a heptapeptide, which is currently of interest for its anti-Mycobacterium tuberculosis activity via a newly discovered novel mechanism of action. Bill designed and had built an apparatus that enabled the facile sampling of deep-sea sediments. This led to the discovery of a novel genus of actinomycetes, Salinispora. From S. tropica, salinosporamide A, a proteasome inhibitor, was discovered and is currently in phase III trials on patients with relapsed multiple myeloma.

$\triangle$ Hiroshi Tomoda

tomodah@pharm.kitasato-u.ac.jp

1 Graduate School of Pharmaceutical Sciences, Kitasato University, 5-9-1 Shirokane, Minato-ku, Tokyo, Japan

2 Department of Pharmaceutical Sciences, College of Pharmacy, University of Illinois at Chicago, 833 South Wood Street, Chicago, IL 60612-7231, USA
Looking back at the publications related to marine/ marine-derived natural product chemistry in the Journal of Antibiotics, the first one appeared in 1972 by Dr. Yoshiro Okami (currently an Emeritus Member of the Journal) and Dr. Takao Okazaki $[1,2]$. Then the number markedly increased in the late 1990s and now the Journal has published over 270 such papers. The decennial totals are: 10 publications in 1972-1980, 3 in 1981-1990, 44 in 1991-2000, 105 in 2001-2010, and 113 in 2011-2020 (April). Dr. Fenical has been a pioneer in this research field. He became an Editorial Board Member of the Journal in 2003. He reported a number of new compounds from marine-derived microorganisms in the Journal [3-10], including antibiotics, arenimycin (2010) [3], nosiheptide (2012) [5], salinamide F (2015) [7], and fluvirucin B6 (2018) [10].

Dr. Fenical is recognized worldwide as a premier expert in marine biology and certainly marine microbiology and he has received many awards including the Paul Scheuer Award in marine natural products chemistry in 1996, the Silver Medal Award in chemical ecology in 1997, the NCI Merit Award in 2003, the American Chemical Society's Ernest Guenther Award in natural products chemistry in 2006, the American Society of Pharmacognosy's Norman R. Farnsworth Research Achievement Award also in 2006, and the Inhoffen Medal (awarded by the Helmholtz Centre for Infection Research and the Technical University at Braunschweig) in 2009 .

$\mathrm{He}$ is a member of the American Society of Pharmacognosy and served as President from 2005 to 2006 . He was inducted as a Fellow of this Society in 2006, and is also a Fellow of the American Association for the Advancement of Science.

\section{Compliance with ethical standards}

Conflict of interest The authors declare that they have no conflict of interest. 
Publisher's note Springer Nature remains neutral with regard to jurisdictional claims in published maps and institutional affiliations.

\section{References}

1. Okami Y, Okazaki T. Studies on marine microorganisms. I. Isolation from the Japan Sea. J Antibiot. 1972;25:456-60.

2. Okazaki T, Okami Y. Studies on marine microorganisms. II. Actinomycetes in Sagami Bay and their antibiotic substances. J Antibiot. 1972;25:461-6.

3. Asolkar RN, Kirkland TN, Jensen PR, Fenical W. Arenimycin, an antibiotic effective against rifampin- and methicillin-resistant Staphylococcus aureus from the marine actinomycete Salinispora arenicola. J Antibiot. 2010;63:37-9.

4. Haste NM, Perera VR, Maloney KN, Tran DN, Jensen P, Fenical $\mathrm{W}$, et al. Activity of the streptogramin antibiotic etamycin against methicillin-resistant Staphylococcus aureus. J Antibiot. 2010;63: 219-24.
5. Haste NM, Thienphrapa W, Tran DN, Loesgen S, Sun P, Nam SJ, et al. Activity of the thiopeptide antibiotic nosiheptide against contemporary strains of methicillin-resistant Staphylococcus aureus. J Antibiot. 2012;65:593-8.

6. Hensler ME, Jang KH, Thienphrapa W, Vuong L, Tran DN, Soubin E, et al. Anthracimycin activity against contemporary methicillinresistant Staphylococcus aureus. J Antibiot. 2014;67:549-53.

7. Hassan HM, Degen D, Jang KH, Ebright RH, Fenical W. Salinamide F, new depsipeptide antibiotic and inhibitor of bacterial RNA polymerase from a marine-derived Streptomyces sp. J Antibiot. 2015;68:206-9.

8. Hassan HM, Boonlarppradab C, Fenical W. Actinoquinolines A and $\mathrm{B}$, anti-inflammatory quinoline alkaloids from a marine-derived Streptomyces sp., strain CNP975. J Antibiot. 2016;69:511-4.

9. Zhou X, Fenical W. The unique chemistry and biology of piericidins. J Antibiot. 2016;69:582-93.

10. Leutou AS, Yang I, Le TC, Hahn D, Lim KM, Nam SJ, et al. Fluvirucin B6, a new macrolactam isolated from a marine-derived actinomycete of the genus Nocardiopsis. J Antibiot. 2018; 71:609-12. 